\title{
Processo de letramento nos Anos Iniciais de ensino: uma pesquisa bibliográfica a respeito da temática e seus aspectos históricos e metodológicos
}

\author{
Literacy process in the Early Years of teaching: a bibliographic research concerning \\ the theme and its historical and methodological aspects \\ El proceso de alfabetización en los Primeros Años de la docencia: una investigación \\ bibliográfica sobre el tema y sus aspectos históricos y metodológicos
}

Recebido: 10/11/2021 | Revisado: 15/11/2021 | Aceito: 15/11/2021 | Publicado: 16/11/2021

\author{
Bruna Alves Nunes \\ ORCID: https://orcid.org/0000-0002-4162-5897 \\ Instituto Educacional Santa Catarina - Faculdade Guaraí, Brasil \\ E-mail: brunaalvesnunes4@gmail.com \\ Denilson Fernandes da Silva \\ ORCID: https://orcid.org/0000-0002-7239-0867 \\ Instituto Educacional Santa Catarina - Faculdade Guaraí, Brasil \\ E-mail: denilsonfernandes2018@gmail.com \\ Poliana Bonfim Santos \\ ORCID: https://orcid.org/0000-0002-0712-6496 \\ Instituto Educacional Santa Catarina - Faculdade Guaraí, Brasil \\ E-mail:polianabonfim22@gmail.com
}

\begin{abstract}
Resumo
O presente artigo tem como objetivo geral analisar a importância do letramento nos anos iniciais de ensino por meio de uma revisão de literatura, o qual utilizou-se critérios de inclusão e exclusão nas bases de dados de pesquisas, servindo assim como viés principal para analisar a documentação abordando a temática de maneira recente e o seu impacto na formação da criança enquanto sujeito alfabetizado e letrado. Cujo letramento é o ensino, desenvolvimento e uso competente da leitura e escrita no ambiente social, enquanto alfabetizado simplifica-se a definição para o sujeito que sabe ler e escrever mediante a utilização de um código. Assim concluiu-se mediante a análise da literatura que a ação de ensinar letrando causa por sua vez dificuldades para o professor alfabetizador sobretudo na tentativa de conciliar a prática pedagógica com a teoria.
\end{abstract}

Palavras-chave: Alfabetização; Letramento; Prática pedagógica; Professor alfabetizador.

\begin{abstract}
This article has as general objective to analyze the importance of literacy in the early years of education through a literature review, which used inclusion and exclusion criteria in research databases, thus serving as the main bias to analyze the documentation addressing the topic recently and its impact on the formation of the child as a literate and literate subject. Whose literacy is the teaching, development and competent use of reading and writing in the social environment, while literate, the definition is simplified for the subject who knows how to read and write through the use of a code. Thus, it was concluded through the analysis of the literature that the action of teaching with literacy in turn causes difficulties for the literacy teacher, especially in an attempt to reconcile pedagogical practice with theory.

Keyword: Literacy; Literacy; Pedagogical practice; Literacy teacher.

\section{Resumen}

Este artículo tiene como objetivo general analizar la importancia de la alfabetización en los primeros años de educación a través de una revisión de la literatura, que utilizó criterios de inclusión y exclusión en bases de datos de investigación, sirviendo así como principal sesgo para analizar la documentación que aborda el tema recientemente y su impacto. sobre la formación del niño como sujeto alfabetizado y alfabetizado. Cuya alfabetización es la enseñanza, desarrollo y uso competente de la lectura y la escritura en el entorno social, mientras que alfabetizada, la definición se simplifica para el sujeto que sabe leer y escribir mediante el uso de un código. Así, a través del análisis de la literatura se concluyó que la acción de enseñar con la alfabetización genera a su vez dificultades para el alfabetizador, especialmente en un intento de conciliar la práctica pedagógica con la teoría.
\end{abstract}

Palabras clave: Literatura; Literatura; Práctica pedagógica; Profesora de alfabetización. 


\section{Introdução}

O avanço tecnológico na sociedade moderna permitiu novas formas de realizar um processo comunicativo devido aos novos veículos de informação e comunicação, permitindo envio de mensagens instantâneas usando para tanto da leitura e da escrita no processo. Nesta perspectiva ver-se a importância de moldar sobre a base de ensino nas séries iniciais ação voltada para alfabetizar e letrar as crianças de modo a possibilitá-las utilizar dessas ferramentas futuramente de forma crítica e consciente.

Assim destaca-se que o conceito de letrar - processo de letramento, no universo pedagógico é recente, surgido em 1986 no livro de Mary Kato, "No mundo da escrita: uma perspectiva psicolínguista" e posteriormente em 1988 por Leda Verdiani Tfouni que lança o termo no universo educacional em seu livro "Adultos não alfabetizados: o avesso do avesso", o qual fazia distinção entre letrar e alfabetizar. O dicionário Aurélio define letramento como sendo "Estado ou condição de indivíduo ou grupo capaz de atualizar-se da leitura e da escrita ou de exercê-las, como instrumentos de sua realização e seu desenvolvimento social e cultural".

Os autores Almeida e Farago (2014) afirmam que quando abordado questões envolvendo letramento e alfabetização, os mesmos apesar de distintos são por sua vez indissociáveis devendo, portanto, caminhar juntos, uma vez que alfabetizar significa ensinar a ler e escrever por meio de um código escrito, enquanto que letramento para os autores é ação educativa capaz de utilizar da leitura e escrita em práticas sociais em contexto real, tornando assim o indivíduo letrado apto para realizar desses de forma deliberada em diferentes contextos. Além do mais, os mesmos iteram sobre a relevância que a construção linguística tem para a criança, dado que faz parte de um processo contínuo de formação cognitiva por meio de interações sociais e orais e de alto impacto na sociedade.

Nesse sentindo, Dias et. al (2016) explana que o letramento está intimamente ligado à utilização da leitura e escrita em atividades de uso social buscando atender as exigências de determinadas situações. Assim, a relação entre leitura e a escrita oportuniza ao indivíduo conhecer o mundo ao seu redor, graças a formação de habilidades oriundas do processo de letramento. Além do mais, Bragança e Sousa (2017) ver que o domínio da leitura e escrita possibilita na nossa sociedade o desenvolvimento de uma cidadania plena, haja vista a promoção de inclusão que os mesmos vêm a promover.

Além do mais, tem-se que "o ato de ensinar a ler e escrever, mais do que possibilitar o simples domínio de uma tecnologia, cria condições para a inserção do sujeito em práticas sociais de consumo e produção de conhecimento e em diferentes instâncias socias e políticas" (Maciel \& Lúcio, 2009, p. 16).

Em Melo (2019) traz sobre a importância do letramento literário na formação juvenil, trazendo informações a respeito do processo transitório da vida infantil para adulta, o qual tem-se a fase da adolescência momento pelo qual passamos por intensas modificações seja elas no campo das ideias ou por novas descobertas e, assim, a aquisição de conhecimento começa a ser concebida de diversas formas.

Assim, justifica-se a temática selecionada devido a relevância que a mesma traz para o universo pedagógico uma vez que o processo de letramento é algo recente e, além do mais letrar é mais que ensinar a utilizar um código é fornecer conhecimento de modo a fazer valia em práticas sociais. Pois, conforme afirma Dias et al. (2016, p. 6).

O letramento refere-se à aprendizagem dos usos sociais das atividades de leitura e escrita, quando assim for exigido em determinadas situações, de modo a atender às necessidades demandadas, promovendo assim um espaço de aprendizagem. O contato com a leitura e a escrita, é a oportunidade que as crianças têm de vivenciar e conhecer o mundo ao seu redor.

Neste sentindo, é fundamental destacar o grande desafio em alfabetizar letrando devido às transformações ocorridas na língua escrita no decorrer do século, onde a escrita passou de objetivo social para exclusivamente escolar, ocultando assim 
sua verdadeira função. Dentre este fato surge à problemática que vivenciamos na realidade atual, onde muitos alunos não são capazes de interpretar e compreender o que leem.

Desta maneira tem-se como objetivo geral da pesquisa analisar a importância do letramento nos anos iniciais de ensino, o qual para tanto será estudado a forma como a Base Nacional Comum Curricular (BNCC) descreve o letramento, além de analisar o surgimento do vocábulo e seu impacto no universo pedagógico e a distinção dos termos letramento e alfabetização.

\section{Metodologia}

O presente artigo caracteriza-se como uma pesquisa bibliográfica, cujo Lakatos e Marconi (2019) definem como sendo o tipo de pesquisa que busca a utilização de materiais já existentes, tais como livros, revistas, artigos e outros veículos informativos a fim de colocar o pesquisador em contato direto com todo o processo de revisão. Desta forma, Manzo (1973, p. 32 abud Lakatos e Marconi, 2019, p. 76), reforça que esse tipo de pesquisa "oferece meios para definir, resolver, não somente problemas já conhecidos, como também explorar novas áreas onde os problemas não se cristalizaram suficientemente", assim a pesquisa bibliográfica não é por sua vez apenas repetição de uma outra pesquisa, mais a ratificação e um novo viés para a temática.

Desta forma, os materiais utilizados para compor a revisão foram selecionados mediante a utilização de operadores booleanos "and", "not" e "or" nas bases de dados Google Scholar e SciELO, devido à aplicabilidade teve-se, portanto, o arranjo da bibliografia, no entanto graças a vasta gama de materiais optou-se por usar critérios de exclusão, sendo-os documentos somente em língua vernácula e que estivesse dentro do período de 2010 a 2020, assim selecionou-se 08 documentos referente a temática e 2 livros que retravam os conceitos de alfabetização e letramento em diversas perspectivas.

Dentre os achados temos Ferreiro (2001), Maciel e Lúcio (2009), Melo (2019), Farago e Almeida (2014), Gontijo (2015), Rodrigues (2020), Forato (2020), Vizentin (2016), Pinheiro e Maciel (2017) e Dias et. al. (2016). Nesses teve-se pesquisa-ação, monografia de especialização, pesquisa de campo e pesquisa bibliográfica e, graças à diversas naturezas das pesquisas escolhidas pode-se então ter melhor posicionamento a respeito da temática, uma vez que possibilitou ponderar sobre em diversos vieses.

\section{Resultados e Discussões}

\subsection{Ensinar letrando: Alfabetizar e letrar}

O processo de ensino-aprendizagem consiste em uma ação de alta complexidade, não somente limitado em ensinar e aprender a utilizar um código, uma vez que envolve diversos componentes tanto sociais quanto comportamentais. E, desta forma, não se restringe apenas a alfabetizar, que para Dias et al. (2016) é a denominação dada ao indivíduo capaz de ler e escrever. Segundo a abordagem de Almeida e Farago (2014) o conceito de alfabetização se tornou motivo de controvérsias metodológicas, necessitando assim ampliar a sua percepção posto que os indivíduos devem compreender a redação e não somente realizar um processo de decodificação de palavras.

Nesse sentindo, Ramos e Gonçalves (2018) relatam que diante da necessidade de ter-se uma nova metodologia de ensino, a qual deveria voltar não somente ao ensino do código, mas também a real compreensão do texto e seu impacto social, surge, portanto, embora associado ao processo de alfabetização, o conceito de letramento. Os quais ainda segundo os autores (apud Soares, 2003) os mesmos acabam por se superpor, podendo até mesmo serem confundidos, sendo tal fato associado aos censos demográficos que buscam analisar e identificar a qualidade de ensino, o que por sua vez acabara por expandir o conceito de alfabetização. 
Assim, para Gontijo (2014) para compreendermos a dimensão do processo de letramento devemos para tanto voltar na história do Brasil Colônia o qual já havia o conceito de analfabetismo, oriundo da grande quantidade de pessoas que não sabiam ler e escrever, embora tal fato no transcorrer da história fora sendo minimizado. Não obstante, conforme a autora (apud Soares, 2002) as pessoas se alfabetizam, no entanto não utilizam da leitura e escrita em seu cotidiano, não usando de tais ferramentas na prática o que acaba por desenvolver o analfabetismo funcional, isto é, indivíduos alfabetizados, porém incapazes de compreender textos de alto grau de complexidade.

Nesta perspectiva, percebe-se que o processo de letramento se constitui como uma área ampla e multifacetada pois o mesmo acontece antes mesmo de ter acesso aos meios educacionais, podendo desta maneira o indivíduo ser letrado e não alfabetizado. Conforme abordagem de Almeida e Farago (2014) no caso da alfabetização tradicional o foco está no código, constituindo assim indivíduos alfabetizados, embora não sejam letrados, pois naquele caracteriza-se como sujeito capaz de codificar e decodificar a língua escrita.

Ainda segundo os autores (apud Tfouni, 1995), durante o processo de alfabetização o sujeito ou grupo ocupa-se, portanto, em adquirir aptidão na linguagem escrita, enquanto o letramento destina-se a analisar os processos sócio-históricos e os impactos do sistema escrito para uma sociedade. Embora, Soares e Ferreira (2019), afirme que o processo de letramento se constitui como uma etapa da alfabetização, pois quando alfabetizados tornam-se capazes de estabelecer relações e interações com aqueles que o circundam, e, assim passa a fazer valia das técnicas de escrita, dando-lhes possibilidade de usar dessas ferramentas para explorar outros conhecimentos.

Desta forma, Rodrigues (2020) afirma que o letramento veio para agregar a ação alfabetizadora, pois muitas vezes encontravam-se alunos que eram apenas alfabetizados, isto é, sabiam ler e escrever, embora não conseguiam estabelecer relação entre o que há escrito e o que se leu. Nesse sentindo, percebe-se a necessidade de estimular os indivíduos durante o processo de ensino a engajarem na busca e aquisição de conhecimentos por meio da prática da leitura, dado que segundo a BNCC (Base Nacional Comum Curricular) é competência básica do ensino fundamental

Exercitar a curiosidade intelectual e recorrer à abordagem própria das ciências, incluindo a investigação, a reflexão, a análise crítica, a imaginação e a criatividade, para investigar causas, elaborar e testar hipóteses, formular e resolver problemas e criar soluções (inclusive tecnológicas) com base nos conhecimentos das diferentes áreas (Brasil, 2017, p. 7).

Nesse sentindo, Rodrigues (2020) pondera que a aprendizagem acontece em diferentes níveis e circunstâncias, pois a aquisição de conhecimento está diretamente vinculada ao processo de evolução do ser humano enquanto indivíduo social, embora a construção de conhecimento não seja algo fácil e tampouco simples. Assim infere-se que durante o processo de ensino deve-se considerar as experiências prévias e o contato que o educando teve com a leitura e escrita, uma vez que em sala de aula há uma heterogeneidade de conhecimentos e vivências particulares.

\subsection{Letramento científico/literário}

Segundo a Base Nacional Comum Curricular (BNCC) o letramento científico constitui-se como sendo parte integrante do processo de ensino e aprendizado ocorrido durante a etapa de ensino fundamental, buscando dessa forma estimular a criança em seu período de transição (6 a 14 anos), transformação e modificação de pensamento estimulando o acesso à diversidade de textos e publicações de cunho científico, podendo dessa forma ser capaz de fazer uso desse conhecimento prévio e ser capaz de gerar novos com base naqueles. Pois, conforme afirma a mesma, nesta etapa a criança está passando por diversas modificações, sejam consigo, com o mundo ou com outrem, o que por sua vez necessita de uma modelagem.

Em estudo realizado por Melo (2019) o qual tratava sobre a importância do letramento literário na formação do indivíduo, o mesmo afirma que o maior contato, experiência com o meio possibilita o amadurecimento do pensamento crítico e fomenta o raciocínio intelectual do jovem, instruindo-o a sobre a importância do contato com a literatura e a leitura sobre a 
gama de textos literários em língua portuguesa. Além do mais, traz que a exposição referente ao letramento focado na literatura evidencia uma melhor formação do jovem enquanto cidadão, além de contribuir positivamente na formação de leitores e criadores de cultura.

Neste aspecto, a Base Nacional Comum Curricular traz consigo competências básicas para a educação, cujo devem valorizar os conhecimentos já formulados buscando explicitá-los aos novos formadores, garantindo dessa forma que os mesmos possam ser capazes de entender a importância destes para a sua formação. Além de exercitar a busca por conhecimento e avanço intelectual trançando abordagem segundo os conhecimentos e métodos científicos.

A esse respeito Soares e Ferreira (2019) afirma que muito dos matérias que estão disponível para a leitura de crianças em formação, não despertam atenção e muito menos excitam ao amadurecimento das mesmas, dado que a literatura encontrada nas escolas trazem como função principal o divertimento e a informação, o que acarreta declínio em relação a sua principal finalidade, que é de despertar no leitor a capacidade crítica e construtiva voltando-se a questão pertinentes e mostrando a significação básica dado ao processo de leitura que é a aquisição de conhecimento e o fomento a formação de valores e significados.

Segundo o pensamento dos referidos autores, o letramento literário destaca-se por alguns aspectos conceituais, as quais voltam-se para a parte de alfabetizar utilizando-se de clássicos literários, incentivando o desenvolvimento crítico por meio da utilização da literatura. Além de propor uma metodologia de alfabetização direcionada a utilização da literatura como parte indissociável do processo educativo, pois mediante a sua valia pode-se incentivar a criança a identificar diversos conceitos a partir da leitura, mas também propor-lhe o desenvolvimento da imaginação e perspectivação de uma realidade oriunda da leitura.

Neste sentindo, Ramos e Gonçalves nos trazem que a criança, ao ter contato com as diferentes linguagens e ao compreendê-las e utilizá-las, apropria-se dos recursos de textualidade que lhe permitem expressar-se com maior clareza e criatividade. A mediação pelas diferentes linguagens na e pela escola possibilitará o aprendizado de leituras mais críticas e das mais variadas possibilidades de organização textual. (Silva, 2010, p.22, apud Ramos \& Gonçalves, 2018, p. 95).

Não obstante, para Melo (2019) a nossa formação enquanto indivíduos sociais é negligenciado no processo escolar o direcionamento para o letramento literário, uma vez que o poder público faz pouco ou nenhum caso em incentivar o investimento para a produção cultural. Assim, o autor destaca que instituições privadas, ao contrário do poder público investem significativamente para a formação desse padrão de ensino, caso este associado ao SESC por meio do programa Jovens em Cena privilegia a arte e a cultura.

Ramos e Gonçalves (2018) atestam que é concebível despertar na criança em processo de formação o gosto pela leitura de material literário, sendo que para tal realização é necessário que seja implementado pelo professor alfabetizador na prática pedagógica a oportunidade de a criança entrar em contato com a infinidade de materiais e manifestações literárias existentes em nossa cultura. Portanto, para que essa realidade ocorra os autores afirma que durante a prática o educador deve sobremaneira direcionar o discente ao encontro com o material literário o ao mundo das letras.

\subsection{Modificações metodológicas ao processo de letramento e alfabetização}

$O$ processo de alfabetização por muito tempo constitui-se no ensino e aprendizagem de um sistema escrito, o qual voltava o olhar da criança para o reconhecimento das palavras e não contribuía para que essas pudessem compreender o texto e a sua significação para o meio social e cultural ao qual estava inserido. E, deste modo restringia apenas a codificação e decodificação de um código, cujo não impactava positivamente para a formação do pensamento crítico da criança. Nesse sentindo, conforme afirma Almeida e Farago (2014) na década de 1980 a maneira como as crianças deveriam ser alfabetizadas passou por modificações, controvérsias e por novas concepções. 
Diante das modificações realizadas no processo de ensino-aprendizagem decorrente na década de 1980 é retomado por Mary Kato em 1985 o conceito de letramento, causando assim impacto sobre o sistema de ensino, cujo aquele designava os indivíduos que eram capazes de exercer e fazer uso social da leitura e escrita. Nesse sentindo, Gontijo (2014) atesta que o processo de letramento não se constitui como um novo método de alfabetização, mas sim um novo olhar para o ensino da leitura e da escrita, pois "letrar é ir além de técnicas, é permitir que o indivíduo abandone a consciência ingênua e passiva e desenvolva a capacidade de pensar criticamente" (Gontijo, 2014, p. 235).

Além do mais o processo de letramento veio para complementar e trabalhar concomitantemente à alfabetização, sendo necessário ao professor alfabetizador a capacidade de conciliá-los para que possa ter um melhor desempenho no ensino das crianças. Neste aspecto, no estudo realizado por Rodrigues (2020), concluiu-se que apesar dos docentes investigados conhecerem a temática do letramento e as principais teorias voltadas a educação de crianças na fase de ensino básico, faltamlhes recursos tecnológicos o que acaba por sua vez comprometendo o processo de ensino das crianças, uma vez que alfabetizar letrando não é uma ação simples, devendo desta maneira ter atenção para atender toda uma classe alfabetizadora.

Segundo a psicolínguista argentina Emília Ferreiro em seu livro alfabetização em processo, explana que durante o desenvolvimento da leitura e escrita enquanto processo cognitivo, a criança constrói hipóteses de modo a justificar as ações tomadas para responder determinadas questões, atribuindo significados específicos como solução de problemas aos quais são impostos, cujos muitas das vezes só podem ser compreendidos conhecendo o contexto o qual está inserido.

Ainda seguindo o pensamento da autora, a mesma afirma que as ações sociais modelam o desenvolvimento da criança enquanto indivíduo alfabetizado, nesse sentindo

O desenvolvimento da alfabetização ocorre, sem dúvida, em um ambiente social. Mas as práticas sociais, assim como as informações sociais, não são recebidas passivamente pelas crianças. Quando tentam compreender, elas necessariamente transformam o conteúdo recebido. Além do mais, a fim de registrarem a informação elas a transformam (Ferreiro, 2001, p. 22).

Neste aspecto a criança não se configura como um sujeito que recebe os dados de maneira passiva, mas sim de um sujeito cognoscente o qual é capaz de transformar os dados recebidos em informações as quais necessitam de um contexto. Segundo Maciel e Lúcio (2009) em análise realizada em um grupo de alunos por uma professora a respeito da produção de uma carta, constatou-se que muitas das crianças apresentavam dificuldades referentes a escrita do gênero. Não obstante houve questionamentos e dúvidas relacionadas a sua produção, uma vez que algumas das crianças perceberam que nesse gênero geralmente escrevia para uma pessoa ausente, nesse sentindo compreende-se que algumas entendia a função social do gênero.

Assim, para Maciel e Lúcio (2009) o professor alfabetizador deve ter domínio do que vai passar aos seus alunos, conduzindo a prática pedagógica de modo a expor ao educando o contato com diferentes gêneros textuais, explicitando para os mesmos o uso e função desses na sociedade. Neste sentindo, as autoras afirmam que as modificações realizadas no processo de ensino-aprendizagem causado pela implementação do modelo de alfabetizar letrando, não se configura como um processo passageiro, mas sim como uma realidade que deve ser concretizada e trabalhada de modo a possibilitar que a criança venha a desenvolver a capacidade de entender as reais funções do texto e do sistema escrito em sua realidade.

Além disso, a alfabetização para Ferreiro é um processo no qual a criança enquanto indivíduo que está sendo alfabetizado constrói por sua vez a realidade por meio da interação que ela tem com o código escrito, cujo maior contato possibilita a incorporação e formulação de novos conceitos e conhecimentos. Assim sendo, tem-se ratificado a necessidade de implementar a ação de ensinar letrando, visto que daria uma melhor base para formação do sujeito. 


\section{Considerações Finais}

Assim percebe-se que o processo de letramento é de fundamental importância para a formação da criança enquanto sujeito social. Nesta perspectiva deve-se não somente analisar a temática e as modificações causadas na maneira como é exercido o ensino e alfabetização dos pequenos, mas também explanar sobre as dificuldades encontradas pelo professor alfabetizador durante a realização da prática pedagógica, posto que há diversas dificuldades referente a temática do letramento, sobretudo devido ao tradicionalismo de ensinar as crianças por meio de processos de memorização conforme enfatiza Maciel e Lúcio (2009) e Ramos e Gonçalves (2018).

Além disso, por meio da literatura analisada pode-se inferir que as modificações realizadas pela ação de ensinar letrando causara apreensão ao educador, pois os mesmos atem-se ao método tradicional de ensino, os quais buscam apenas alfabetizar, isto é, ensinar a ler e escrever por meio de um código, deixando isento a real função do código e o seu impacto para a formação do sujeito.

Apesar da temática do letramento está presente em nossa sociedade a pouco mais de 40 anos, a mesma ainda é motivo pertinente para debates oriundo da indispensável necessidade de compreender que as modificações causadas para formação do leitor vão além do ensino de um código, pois servem como estimulante para a construção do pensamento crítico do indivíduo, pois o mesmo ultrapassa a ideia de somente ensinar a ler e escrever, codificar e decodificar o código, pois direciona-se para a real função da leitura para nosso cotidiano e para a formação social.

Nesse sentindo, destacamos que o ensino mediante a utilização do processo de letramento, voltando-se a alfabetizar letrando, privilegia o acesso à cultura e ao meio científico, sem que seja posto um em detrimento do outro, o que desta forma promove quando conciliados uma maior qualidade de ensino. Pois a promoção cultural incita o jovem leitor, educando, a buscar novos conhecimentos, quando o processo de ensino a desperta curiosidade.

\section{Referências}

Almeida, V. F. \& Farago, A. C. (2014). A importância do letramento nas séries iniciais. Cadernos de Educação: Ensino e Sociedade. Bebedouro-SP. 1 (1). <https://www.unifafibe.com.br/revistasonline/arquivos/cadernodeeducacao/sumario/31/04042014074426.pdf

Brasil. (2017). Ministério da Educação (MEC). Base Nacional Comum Curricular- BNCC. <Base Nacional Comum Curricular - Educação é a Base (mec.gov.br)>

Dias, I. P.et al. (2021). Letramento na educação infantil. Seminário de Estágio Supervisionado do Campus Anápolis de CSEH-UEG: as decisões nas políticas

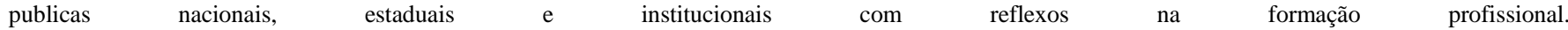
<https://anais.ueg.br/index.php/seminariodeestagioccseh/article/view/7741/5257>.

Ferreiro, E. (2001) Alfabetização em processo.( 14ª ed.) São Paulo: Editora Cortez, 136.

Gontijo, L. S. (2015). Reflexões sobre a importância do letramento na educação infantil. Sistema Integrado de Publicações Eletrônicas da Faculdade Araguaia - SIPE. 3(1). http://www.fara.edu.br/sipe/index.php/anuario/article/download/279/252>

Lakatos, M.. \& Marconi, M. D. A. (2017). Metodologia Científica. $7^{\text {a }}$ ed. Grupo GEN.

<https://integrada.minhabiblioteca.com.br/reader/books/9788597011845/epubcfi/6/2\%5B\%3Bvnd.vst.idref\%3Dcover\%5D!/4/2/2\%4051:1>

Maciel. F.I.P.\& Lucio, I. S. (2009). Os conceitos de alfabetização e letramento e os desafios da articulação entre teoria e prática. In CASTANHEIRA, Maria Lucia. Et al. Alfabetização e letramento na sala de aula. (2 ${ }^{a}$ ed.). Belo Horizonte: Autêntica Editora: CEALE. 13-33.

Melo, O. M. S. D. (2019). A importância do letramento literário para a formação juvenil a partir da experiência do grupo jovens em sena do SESC Santo Amaro no Recife. Recife: Unidade Acadêmica de Educação a Distância e Tecnologia, Universidade Federal Rural de Pernambuco. <DSpace da UFRPE: A importância do letramento literário para a formação juvenil a partir da experiência do grupo jovens em cena do SESC Santo Amaro no Recife>

Pinheiro, I. S. B. \& Maciel, E. R. D. S. (2017). Navegando no letramento na educação infantil. Revista Eletrônica Mutações. v.1, n.1. <https://www.periodicos.ufam.edu.br/relem/article/download/3591/3158>

Ramos, E.F. \& Gonçalves C.R. (2018). A importância do letramento no ensino Fundmental. Congresso Nacional de Linguística e Filologia. Rio de Janeiro, RJ. Anais Eletrônicos... Rio de Janeiro, RJ: CiFEFiL<006.pdf (filologia.org.br) > 
Research, Society and Development, v. 10, n. 15, e204101523095, 2021

(CC BY 4.0) | ISSN 2525-3409 | DOI: http://dx.doi.org/10.33448/rsd-v10i15.23095

Rodrigues, E. (2020). A importância do letramento no processo de Alfabetização. Rio Negro: Universidade Federal Tecnológica do Paraná. < http://repositorio.utfpr.edu.br/jspui/handle/1/25157>

Soares, L. L. \& Ferreira, B. M. (2019). Importância do letramento para a formação do leitor. Faculdade Alfredo Nasser. <a-importância-do-letramentoliterário-para-a-formação-do-leitor.pdf (unifan.edu.br)> 